1303

\section{RESPIRATORY ASSISTANCE AT THE NEWBORNS T OVER 5 YEARS}

D.M. Doagi, H. Bouzidi, S. Ben Jmaa, S. Blibech, A. Abdelli, M. Ben Romdhane

Neonatology, Military Hospital, Tunis, Tunisia

The authors analyze the results of 5 years in the field of respiratory neonatal assistance from 2005 till 2009.

337 newborns were analyzed retrospectively whom 200 boys and 137 girls Out born represents 35,6 \% of hospitalizations (120/337).

The immature infants represent $68,2 \%$ of studied cases (230 cases) among which 80 extremely immature infants ,

The indications of assisted ventilation are represented by the Hyaline membrane disease in 92 cases $(37,3 \%)$ the perinatal asphyxia in 50 cases $(14,8 \%)$, the alveolitis in 75 cases $(22,3 \%)$, in 15 cases $(4,5 \%)$, persistent pulmonary high blood pressure in 33 cases $(9,8 \%)$ and vital distress in 72 cases $(21,3 \%)$.

The techniques of artificial respiration were principally conventional in 198 cases $(58,8 \%)$, not conventional in 139 cases (41,2\%) among which 133 newborn babies benefited of NCPAP $(39,5 \%)$ and $6(1,8 \%)$ of an artificial breathing by vibration with high frequency.

The exogenous surfactant was used in 95 cases $(28,2 \%)$, indication was principally the illness of hyalines membranes in 85 cases $(25,2 \%)$ and destruction of the secondary endogenous surfactant in a contagious alvéolite or a méco The monoxide of inhaled nitrogen was used at 30 sick.

The SE association and NOi was 17 times used in front of presence of resistant hypoxémie.

The total mortality rate is is $35,3 \%$. The rate mortality of the premature is $28,2 \%(65 / 230)$. The major after-effects are (25 cases) cerebral paralysis with a detachment of 5 years.

\section{4}

\section{SELF MEDICATION IN CHILDREN AT THE DISTRICT OF TUNIS (TUNISIA) : FOCUS ON ANTIBIOTIC SELF MEDICATION}

F.C. Jemaa ${ }^{1}$, A. Khaldi ${ }^{1}$, L. Bessioud ${ }^{1}$, J. Borhene ${ }^{1}$, T. Akkad ${ }^{1}$, G. Ltaief ${ }^{2}$

${ }^{1}$ Children's Hospital of Tunis, ${ }^{2}$ Pharmacy Department of Tunis, Tunis, Tunisia

Self medication is a great problem in Tunisia. Children are strongly susceptible to the irrational use of drugs without medical evaluation. Focusing on this problem in the paediatric population is rare.

Objective: to determine a 1-day prevalence of self medication in children in five private pharmacies in the district of Tunis and analyze factors related to self medication, especially for antibiotics.

Methods: observational study of a simple random sample of parents of children acquiring medicaments as a self medication in five private pharmacies chosen arbitrary. Non consent parents were excluded. Included subjects were interviewed by a medical investigator about demographic data of their self prescribed children, nature of drugs acquired and reasons of self medication.

Results: among 224 total delivered treatments prescription for paediatric population, the prevalence of self medication was $62,5 \%$. The main groups of self-prescribed drugs were: analgesic/antipyretic and anti-inflammatory drugs $(65 \%)$, systemic antibiotics (48\%), and drugs acting on the respiratory tract (38\%). Amoxicillin (55\%) and cephalosporin $(26 \%)$ were the most self-prescribed antibiotics. Self-prescribed children were aged less than 1 year in $35 \%$ and they suffer, according to parents, from a low respiratory tract infection in $57 \%$, a pharyngitis/ tonsillitis in $17 \%$ and an isolated fever in $10 \%$. Parents, especially mothers $(61 \%)$ and drugstore employers (20\%) were mostly responsible for self medication.

Conclusion: Prevalence of self medication in the paediatric population is high. Antibiotics, especially amoxicillin and cephalosporin are largely selfprescribed. Public health interventions aiming to reduce this practice are urgent in our country 